\title{
Beyond the Words in Print: Identity Construction in Messages of Condolence
}

\author{
By Rita Akele Twumasi
}

\begin{abstract}
Death is part of human existence. When a person hears the news of someone's death, it is very common for that person to express their feelings about it. This feeling is in the form of condolences which express the speaker's sorrow, and condolences fall into the category of speech act. Semantically, condolences have a social meaning which refers to language use. Identities are created in relationships with others, and condolences are major platforms for the construction of identities, in that, existing relationships are, clearly, manifested in the messages that sympathizers expressed. Using a qualitative approach, the study analyzed twenty condolence messages which were purposely sampled from condolence messages posted in the portals of International Centre for Theoretical Physics (ICTP), when one of its members passed away. The analysis of the data revealed two main identity types enacted for the deceased: role identity and Social Identity. The major Role identity enacted, metaphorically, was Father while the least role was Achiever. Second, identity as an International Figure was dominant with the Social roles, but Good Personality was used less frequently. The present study adds to studies in identity construction, in general, and studies in condolence messages, in specific.
\end{abstract}

\section{Introduction}

Death is a natural part of human life, in that, little can be done about its existence. ${ }^{1}$ It awaits every living thing on this earth. No matter what form it takes, death is always very painful. Death is almost always unscheduled"2 since, sometimes, we least expect the occurrence of death in our lives. When death occurs, its announcement to affected individuals becomes very difficult. When a person hears the news of someone's death, it is very common for that person to express their feelings about it. ${ }^{3}$ This feeling is in the form of condolence which expresses the speaker's sorrow. If the person who hears the death news does not show any reaction or does not express their feelings, in most cultures, such a person is considered unsympathetic. Death may be announced without prior

"Assistant Lecturer, Department of Communication Studies, University of Cape Coast, Ghana.

1. T. R. Williams, "Linguistic politeness in expressing condolences: a case study," Social Science \& Humanities 23, no. 1 (2015): 1-19.

2. R. E. Clark and E. E. LaBeff, "Death telling: managing the delivery of bad news," Journal of Health and Social Behavior 23, no. 4 (1982), 367.

3. Behman et al., 2013. 
indication, leaving the speaker with no time to prepare. ${ }^{4}$ In delivering or talking about bad news, ${ }^{5}$ there is a tension between showing support and involvement by speaking about it at length, and showing respect for privacy by closing the topic quickly. Bereavement is a time when people may be particularly vulnerable; hence, failure to express condolences appropriately can damage personal relationships if the expression of sympathy is perceived as insensitive or inadequate. ${ }^{6}$

The expression of condolence falls into the category of speech act, the theory which has been developed mainly by Austin (1962) and Searle (1969; 1979). Speech acts are defined as actions performed via utterances in an actual situation of language use, bringing the functions the speaker intends to the hearer(s) to take or to interpret. Austin's (1962) classification is into three different meanings: locutionary (what is said), illocutionary meaning (the intended meaning), and perlocutionary meaning (the effect of one's words on the listener). In a classification of illocutionary act, there is an elaboration of the taxonomy into five categories: ${ }^{7}$ first, representatives or assertives (the description of states or events, e.g., reports, assertions, claims); second, directives (e.g., requests, orders, suggestions, commands, inviting, i.e. asking the listener to do something in the future); third, commisives (e.g., promises, threats, offers, swearing, i.e., committing oneself to do something in the future); fourth, expressives (e.g., apologies, expressing gratitude, congratulating, i.e., expressing one's psychological state of mind), and fifth, declaratives (e.g., declaring, appointing, i.e. bringing about a change). Of these, expressive speech acts reveal psychological states of mind and express personal attitudes and feelings. They deal with social and interpersonal relations. The list of expressives includes greetings, thanks, congratulations, condolences, and apologies, and politeness considerations are among the main factors that determine the realizations of these speech act.

Speech acts are speech functions that are realized by way of words, ${ }^{8}$ and that being able to say the right thing to the right person at the right time would be a great social accomplishment. ${ }^{9}$ Thus, many social factors such as age, gender, class, culture, and status play important role in achieving effective communication. Habermas (1981) sees the importance of Searle's approach in that he considers language as a means for coordinating action. In sum, the theory of speech acts rests on the premise that the minimal unit of human communication is not a

4. K. Elwood, "I'm so sorry': a cross-cultural analysis of expressions of condolence," The Cultural Review, Waseda Commerical Studies Association, (Bulletin of Universities and Institutes) 24 (2004): 101-126.

5. Clark and LaBeff, 1982.

6. Elwood, 2004.

7. J. A. Searle "A classification of illocutionary acts," Language in Society 5, no. 1 (1976): $10-15$.

8. G. Yule, Pragmatics (Oxford: Oxford University Press, 1996), 47.

9. Ibid. 
sentence or other expression, but the performance of certain kinds of language acts, such as requests and promises.

This speech act of condolence is used to express the speaker's sorrow at the news of someone's death. ${ }^{10}$ Speech act of condolence is related to the expressive classification; it is used to express the interlocutor's sorrow at the news of the death of someone. ${ }^{11}$ Condolences are formal expressions of sympathy offered to people after the death of a loved one, and condolence phrases are designed to convey sympathy for the bereaved person, but, as a general rule, the emotion behind the phrase is often more important than the wording itself. ${ }^{12}$ Many people are aware that it is very difficult to give condolence phrases without sounding slightly clichéd. Condolence expressions consist of utterances such as "sorry for your loss", "deepest sympathy" and many others. These condolence expressions are neutral enough to be appreciated for anyone regardless of religious beliefs.

Semantically, condolences have a social meaning which refers to the language use, and this is to establish social relations and roles; condolences are not just expressions of sympathy, but they are, also, acts of encouragement. ${ }^{13}$ Condolence responses are classified according to semantic formula which is analogous to Olshtain and Cohen's (1983) who found five types of semantic formulas for apologies: a) Acknowledgement of the death: it includes certain interjections such as 'no' and 'oh'; b) Expression of sympathy such as "I am participating in your sorrow"; c) Offer of assistance like "is there anything I can do?"; d) FutureOriented remarks such as "try not to get depressed", and e) Expression of concern like "you must care for yourself". These were the classical categories that most researchers based their investigation of offering condolences on; however, semantic formula such as "expression of empathy", "statement of lacking words", "religion expressions", "expression of surprise", "related questions", "statement of not knowing", and others have been developed lately. ${ }^{14}$

Because conversations surrounding death are not institutionally prescribed, death is almost always unscheduled, and the interactions of the various participants are only partially regulated, there might be the interplay of social and personal diminuendos. ${ }^{15}$ Just as individuals form, transform, and modify how they define themselves and others in the context of work-based situations and

10. B. Lotfollahi and A. Rasekh, "Speech act of condolence in Persian and English," Studies in Literature and Language 3 no. 3 (2011), 139-145.

11. J. R. Searle, Speech acts: an essay in the philosophy of language (Cambridge: Cambridge University Press, 1969).

12. E. M. Yahya, "A study of condolences in Iraqi Arabic with reference to English," Adab Al- Rafidayn 57 (2010): 47-70.

13. A. Mwihaki, "Meaning as use: a functional view of semantics and pragmatics," Swahili Forum 11 (2004): 127-139.

14. Elwood, 2004.

15. Clark and LaBeff, 1982. 
activities, ${ }^{16}$ expressing condolences also provide a platform for the construction of identities in the sense that identities are created in relationships with others, ${ }^{17}$ and condolences are major platforms for signaling the kinds of relationship that the sympathizers had with the deceased. The present study, therefore, seeks to examine the kinds of identity that are enacted for the deceased in condolence messages by sympathizers. In the rest of the paper, I consider the conceptual framework (theoretical and empirical studies), methods, and analysis and discussion. Implications of the study will also be added.

\section{Conceptual Framework}

This section, first, considers the theoretical perspective that underpins the present study, the Social Identity Theory, and then, adds relevant previous studies on condolences.

\section{Theoretical Perspective}

The theory that informs the present study is the Social Identity Theory (SIT). SIT rests on the premise that individuals define their own identities with regard to social groups, and such identifications work to protect and bolster selfidentity. ${ }^{18}$ The creation of group identities involves both the categorization of one's "in-group" with regard to an "out-group", and the tendency to view one's own group with a positive bias vis-à-vis the out-group. The result is an identification with a collective, depersonalized identity based on group

16. J. E. Dutton, L. M. Roberts and J. Bednar, "Pathways for positive identity construction at work: four types of positive identity and the building of social resources," Academy of Management Review 35, no. 2 (2010): 265-293; Ibarra, "Provisional selves: experimenting with image and identity in professional adaptation," Administrative Science Quarterly 44, no. 4 (1999): 764-791; Pratt, "The good, the bad, and the ambivalent: managing identification among Amway distributors," Administrative Science Quarterly 45, no. 3 (2000): 456-493; Pratt, Rockmann and Kaufmann, "Constructing professional identity: the role of work and identity learning cycles in the customization of identity among medical residents," Academy of Management Journal 49, no. 2 (2006): 235-262.

17. Gecas, "The self-concept," Annual Review of Sociology 8 (1982): 1-33; Gergen, The saturated self: dilemmas of identity in contemporary life (New York: Basic Books, 1991).

18. Tajfel, "Social categorization, social identity, and social comparison," In Differentiation between Social Groups: Studies in the Social Psychology of Intergroup Relations, edited by H. Tajfel. London: Academic Press, 1978, 61-76; Tajfel and Turner, "The social identity theory of intergroup behavior," in Psychology of Intergroup Relations, edited by S. Worchel and W. G. Austin (Chicago, IL: Nelson-Hall, 1987), 7-24. 
membership and imbued with positive aspects. ${ }^{19}$ Positive in-group bias can be explained because the in-group comes to take on a self- relevant role, where persons define themselves through the group. In Social Identity Theory, the self is reflexive in that it looks back on itself as an object and categorizes, classifies, or names itself in particular ways that contrast itself with other social categories or classifications. This is the process of self-categorization. In Social Identity Theory, self-categorizations are cognitive groupings of oneself and an aggregate of stimuli as identical, in contrast to another group of stimuli. Persons who are similar to the self with respect to these stimuli are grouped with the self (the in-group); persons who differ from the self are classified as the out-group. ${ }^{20}$

The self-categorizations depend upon a named and classified world. Among the class terms learnt within a culture are symbols that are used to designate "positions," the relatively stable, morphological components of social structure that are termed roles. Persons acting in the context of social structure name one another and themselves in the sense of recognizing one another as occupants of positions. ${ }^{21}$ This naming invokes expectations with regard to each other's and one's own behaviors. ${ }^{22}$

The self-view that emerge from the reflexive activity of self-categorization in terms of membership in certain groups or particular roles comprise one's identities. Thus, while the question of how one classifies oneself is different depending upon the theory that is used (group or role), individuals view themselves in terms of shared social categories. ${ }^{23}$

The theory also holds that an individual has as many different identities as self-categorizations and that, as a set, these different identities make up the selfconcept. For Social Identity Theory, the multiple identities are the different social categories to which the self belongs. Given multiple identities, there are relationships among the different identities which will be activated in a situation. In Social Identity Theory, the different identities are organized into a hierarchy of inclusiveness, with three levels which are generically attended to: a superordinate level such as "human," an intermediate level such as an "American," and a subordinate level such as a "Southerner." 24 The levels are dynamic and

19. Turner, Hogg, Oakes, Reicher, and Wetherell, Rediscovering the social group: a selfcategorization theory (Oxford: Blackwell, 1987).

20. Turner, "Social categorization and the self -concept: a social cognitive theory of group behavior," in Advances in Group Processes: Theory and Research, edited by E. J. Lawlery (Greenwich, CT: JA, 1985).

21. S. Stryker, Symbolic interactionism: a social structural version (Menlo Park: Benjamins, 1980).

22. Ibid; McCall and Simmons, Identities and interactions: an examination of human associations in everyday life (New York: Free Press, 1978).

23. Ibid.

24. J. E. Stets and P. J. Burke, "Identity theory and social identity theory," Social Psychology Quarterly 63, no. 3 (2000), 231. 
contextual, depending upon the salience of the different classifications. ${ }^{25}$ Different identities become active as the situation changes and relevant self-categorization stimuli change. ${ }^{26}$

It must be acknowledged, here, that the process of identity construction is inherently dialogic in nature ${ }^{27}$ in the sense that our senses of ourselves are fashioned in relation to the identities of others-sometimes, in concert with them; sometimes, in opposition to them, but always in relation to them. ${ }^{28}$ Being and doing are both central features of one's identity. Thus, in expressing condolences, there is being and doing. ${ }^{29}$ The present study seeks to examine the kinds of identity that are enacted for the deceased both through what the deceased was (being) and what he did (doing), which are anticipated to be expressed through the condolence messages that were sent to the portal of ICTP, when one of its members passed away.

The Social Identity Theory has been employed in many studies. For instance, in a study, it was examined how moral standards and moral judgements play a role in the regulation of individual behaviour within groups and social systems. They investigated the importance of morality for group-based identities and intra-group behavioural regulation. Their study revealed convergent evidence of the centrality of moral judgements for people's conceptions of the groups they belong to, and demonstrated the importance of group-specific moral norms in identifying behaviours that contribute to their identity as group members. ${ }^{30}$

In academics, how identities are enacted, has been investigated. A study investigated identity conflict or interference by focusing on a new identity combination, the woman and scientist identities. The study examined the influence of identity centrality, or importance, as a predictor of interference and moderator of the relation between interference and well-being and science performance. Supporting hypotheses, greater identity interference was related to lower levels of performance and well-being. Furthermore, woman centrality was unrelated to interference for those with a central scientist identity, but for those without a central scientist identity, they were positively related. Although central identities were related to positive outcomes in the absence of interference, the outcomes of all women suffered when interference was high, contrary to the

25. Turner, "The role and the person," American Journal of Sociology 84 (1987): 1-237.

26. Stets and Burke, 2000, 231.

27. Bakhtin, "Discourse in the novel," translated by C. Emerson and M. Holquist, in The Dialogic Imagination, edited by M. Holquist (Austin: University of Texas Press, 1981), 259-422.

28. G. A. Hull and J. Zacher, "Enacting identities: an ethnography of a job training program," Identity 7, no. 1 (2007): 71-102.

29. Stets and Burke, 2000.

30. N. Ellemers, S. Pagliaro and M. Barreto, "Morality and behavioural regulation in groups: a social identity approach," European Review of Social Psychology 24, no. 1 (2013): 160-193. 
hypothesis. ${ }^{31}$ Replicating past work, another study demonstrated that introducing negative stereotypes about women's Math performance activated participants' female social identity and hurt their math performance (i.e., stereotype threat) by reducing working memory. Moving beyond past work, it was also demonstrated that concurrently presenting a positive self-relevant stereotype (e.g., college students are good at Maths) increased the relative accessibility of female college students' identity and inhibited their gender identity, eliminating attendant working memory deficits and contingent math performance decrements. In addition, subtle manipulations in questions presented in the demographic section of a math test eliminated stereotype threat effects that result from women reporting their gender before completing the test. The work identified the motivated processes through which people's social identities became active in situations in which self-relevant stereotypes about a stigmatized group membership and a nonstigmatized group membership were available. In addition, it demonstrated the downstream consequences of this pattern of activation on working memory and performance. ${ }^{32}$

Also, there was an analysis of the kinds of identity that were enacted with some non-verbal cues. Using the identity theory, the researchers examined a data set of four (4) presentations by M. A. Teaching Communicative Skill students. The study identified several non-verbal cues which were further categorized into five main groups - physical appearance, gestures, face and eyes behaviours, vocal behaviours and space environment. The researchers observed that each of the presenters A, B, C, and D enacted distinct identities and in some cases common identities. ${ }^{33}$

Furthermore, a study investigated the experience of reversal conceptual transfer among Iranian learners of English as a foreign language, specifically in the construction of double identities in studying a foreign language. He employed a qualitative approach, by using open-ended questionnaires for 65 undergraduates at the University of Isfahan and 45 interviews conducted in a private language school. A key finding of the study was that most of the participants had partially experienced reversal conceptual transfer. On the other hand, some of the participants did not seem to have constructed a new foreign language identity

31. I. H. Settles, "When multiple identities interfere: the role of identity centrality," Personality and Social Psychology Bulletin 30, no. 4 (2004): 487-500.

32. R. J. Rydell, A. R. McConnell and S. L. Beilock, "Multiple social identities and stereotype threat: imbalance, accessibility, and working memory," Journal of Personality and Social Psychology 96, no. 5 (2009): 949-966.

33. K. W. Gyasi, Kongo, B. K. Agbenyo, W. Y. Lumor, P. Aopare and C. Koufie, "Identity and non-verbal communication: the case of UCC students on Master of Arts teaching communicative skills programme," African Journal of Applied Research (AJAR) 2, no. 2 (2015): 51-60. 
in English, but others who did had a more positive attitude towards their English identity. ${ }^{34}$

Introducing another variable, gender, there was an investigation of the relationship that existed among college student's social identity, online learning performance, life satisfaction and social identity. The study employed 490 questionnaires using Jonathan $\mathrm{M}$. Cheek relational identity orientation scale for the AIQ. The results indicated that the demographic features of students had different influence on their social identity, and the effect of online learning performance and life satisfaction on social identity shows a significant difference. Specifically, the study found that life satisfaction of girls was higher than that of boys. Also, students of associate degree had a higher social identity than students of bachelor degree. Third, both the improvement of online learning and life satisfaction could promote the enhancement of social identity, and the effect of improving online learning is more significant. ${ }^{35}$ Also, a study investigated whether the implementation of intercultural movie clips could contribute to improving the personal identity, and impacting positively on L2 identity of participants in the English as a foreign language (EFL) context of Iran. Thus, two intact classes were assigned to the control and experimental group, each containing thirty students. This quasi-experimental study was implemented on the pre-test post-test equivalent-group design. Drawing on quantitative and qualitative analysis, using two questionnaires and a semi-structured interview, the results indicated that positive changes took place in the personal and second language identity of the participants. More specifically, the participants moved from a closed community of practice in which self was seen from one horizon to an intercultural community of practice in which others were seen besides self. The changing community provided by movie clips had an impact on the participants' views and trends. Thus access to new social, cultural, and linguistic resources resulted in the adoption of new identities. ${ }^{36}$

Still on academics but with a focus on graduate students, there was an exploration on the experience that three East Asian international Graduate Teaching Assistants (GTAs) encountered at a Midwestern teaching and research institution in the US, by examining the perceptions, difficulties and challenges, and future career choices that constructed the learning, social and teaching experiences of these three East Asian international GTAs. Data were collected through in-depth individual semi-structured interviews, informal chats, and

34. R. Gholaminejad, "Identity construction and reversal conceptual transfer among Iranian EFL learners," HOW 24, no. 2 (2017): 1-15.

35. Z. Mingfang and W. Qi, "Empirical research on relationship between college students' social identity and online learning performance: a case study of Guangdong province," Higher Education Studies 8, no. 2 (2018): 97-106.

36. A. Nematzadeh and M. H. Narafshan, "Construction and re-construction of identities: a study of learners' personal and L2 identity," Cogent Psychology 7(2020): 1-19. 
the analysis of relevant documents. The findings of the study revealed identities such as academic identity, social identity and teacher identity of the participants. ${ }^{37}$ Furthermore, Using the Social Identity Model of Identity Change (SIMIC), a study investigated the process of academic identity construction among doctoral students. Through thematic analysis of semi-structured interviews with $22 \mathrm{Ph} . \mathrm{D}$. candidates, they observed that the identity construction process relied on a person's perception of a navigable pathway between their current self and their future self. Importantly, participants who were able to access multiple identity resources were more likely to perceive a navigable pathway to a future professional self (e.g., as an academic), unless they perceived these identities to be incompatible with those held by leading members of the profession (e.g., their supervisors). The study suggested that the identities that people are able to access as they progress in their careers may play an important role in their ongoing professional identity construction and career success. ${ }^{38}$

On the professional front, the process of professional identity construction of two English as a foreign language student-teachers from a sociocultural theoretical lens was investigated. A qualitative case study was conducted through personal narratives, semi-structured interviews, and a focus group, and the data were analyzed using a grounded theory approach. The results show that the process of student-teachers' professional identity construction was unstable and dynamic, and was shaped by inter-related personal and external factors such as self-image, learning environment, and practicum experiences. ${ }^{39}$ Also, an examination of the process of professional identity construction in undergraduate nursing students during their education was conducted. Using a qualitative research which was anchored in the Historical-Cultural framework, the study used Twenty-three undergraduate nursing students who were interviewed, with a semi-structured script. The study showed four main themes: first, the subjects were found in a movement to become a nurse: from previous experiences to entering the courses. Second, the nursing professor in the construction of the undergraduate's professional identity: a two-way mirror. Third, Pedagogical relationship: instrument for constructing the student's professional identity and, four, Historical-cultural conditions: space for the construction of the student's professional identity. Thus, it was concluded in the study that the construction of the students' professional identity is limited to the material conditions of existence, translating appropriation to the intrapsychic scope of elements that

37. J. Gao, Exploring the identity negotiation of East Asian graduate teaching assistants: a case study of academic identity, social identity and teacher identity (University of Kansas, 2019).

38. S. V. Bentley, K. Peters, S. A. Haslam and K. H. Greenaway. "Construction at work: multiple identities scaffold professional identity development in academia," Frontiers in Psychology 10, no. 628 (2019): 1-13.

39. D. Salinas and M. Ayala, "EFL student-teachers' identity construction: a case study in Chile," HOW 25, no. 1 (2018): 33-49. 
occur, first, in the inter-psychological space of interactions. Nursing professors can become a paradoxical mirror, with one face to be imitated and the other, which materializes meanings of a model not to be followed. This construction is also influenced by the conditions of professional practice and university education. ${ }^{40}$

Still focusing on professional identity but shifting attention from novice as seen in the earlier studies, the identity construction of Business English teacher from the perspective of ESP was examined by focusing on teacher identities in Chinese Business English teachers construct, and the construction of these identities. They observed the teaching activities in four courses offered by Guangdong University of Foreign Studies for their first-year postgraduate students of Business English major. Based on Needs Analysis and learning-centred approach of ESP theory, the study showed three identities that Business English teachers should construct: teaching practitioners and researchers, learners, and businesspeople. Again, it was established in the study that teacher identity is of great significance to the successful construction of multidimensional teacher identities for Business English teachers and to the realization of their professional development. Also, Business English teachers must first be teachers who impart knowledge and solve doubts of the students, and the main function of teachers is the practitioner of teaching. ${ }^{41}$

Identity construction and negotiation in language institute of four Indonesian teachers of English for Specific Purposes (ESP) was investigated, through an exploration of life-history interviews. The findings highlighted that the participants constructed ESP teacher identity through acquiring subject knowledge via professional development activities within the workplace community or surrounding educational institutions. A sense of intrinsic fulfilment also enveloped these participants, as their self-positionings, as ESP teachers in the language institute, contributed to their professional development. On the other hand, the participants showed subordination to the students' demands for learning ESP as ESP courses in the context of language institute served as an independent and customized program designed for specific students. However, that condition encouraged the participants to develop their professional practices by making some course adjustment based on the result of teacher-student dialogue, in order to meet the students' needs. ${ }^{42}$

40. R. S. Lima, R. S., M. A. I. Silva, L. S. Andrade, F. S. N. Góes, M. A. Mello and M. F. C. Gonçalves, "Construction of professional identity in nursing students: qualitative research from the historical-cultural perspective," Revista Latino-Americana de Enfermagem 28 , no. 3284 (2020).

41. G. Guihang and Z. Miao, "Identity construction of Chinese business English teachers from the perspective of ESP theory," International Education Studies 12, no. 7(2019): 20-27.

42. A. W. Mahendra, "Constructing identity: experiences of Indonesian ESP teachers in a language institute," English Language Teaching Educational Journal 3, no. 3 (2020): 229240. 
Again, the enactment of national identities have been investigated. First, there was an examination of how Dominican Americans whose members are Hispanic, American, and, largely, of African descent did negotiate distinctive issues of identity in the United States. The study showed that language was central to these negotiations, both as a symbol of identity and as a medium through which the construct and display of local social meanings were carried out. That is, Dominican Americans used linguistic forms from multiple varieties of two codes, Spanish and English, to situationally activate various facets of their multiple identities. This multi-variety linguistic and interactional construction of identities undermines implicit assumptions of uniformity and essentialism in U.S. linguistic and ethnic/racial categories, particularly in the construction of the category "African American". ${ }^{43}$ Furthermore, a study succinctly reviewed the main developments in Spain's contemporary history in order to provide a background for the discussion of the various identities expressed by citizens in Catalonia. A segmentation analysis reviewed the various forms of Catalan selfidentification, among which 'duality' was to be underlined. Single Identity (values 1 and 5), Dual Identity (values 2, 3 and 4), (Values 6 and 7 had been aggregated), Catalan Identity (values 1 and 2), Shared Identity (value 3) and Spanish Identity (values 4 and 5) were also found. ${ }^{44}$

Identity constituting discourses have also been analysed. The aim of the paper was to show how fairly abstract reasoning about discourse and identity could be translated into a method of research, concentrating on narratives that were told about the other, namely Turkey's past (ideational function), about the Turco-European relations (relational function), and the self, that is, about Europe (identity-function). His impression from the first exploratory look at the discourse was that narratives were quite frequent when it came to the representation of the Turco-European relations. ${ }^{45}$

Related to national identity is ethnicity identity. There was an exploration of the relationship between value systems and ethnic identity formation and how the difference in value systems influences the salience of identity and conflict. Through narratives from in-depth interviews, he analyzed group identity formation and their impact on conflict. The study revealed that the role of salient identity was used in the denigration of others, and through narratives, an enemy was created out of the "other" and violence towards them justified. ${ }^{46}$

43. B. Bailey, "the language of multiple identities among Dominican Americans," Journal of Linguistic Anthropology 10, no. 2 (2001): 190-223.

44. L. Moreno, A. Arriba, and A. Serrano, "Multiple identities in decentralized Spain: the case of Catalonia," Regional \& Federal Studies 8, no. 3 (1998): 65-88.

45. R. Hülsse, "The discursive construction of identity and difference: Turkey as Europe's other?" Discussion paper presented at the ECPR Joint Sessions of Workshops (Workshop: The Political Uses of Narrative) (Mannheim, 1999), 26-31.

46. C. M. Aapengnuo, Threat narratives, group identity and violence: a study of the Dagomba, Nanumba and Konkomba of Northern Ghana (George Mason University, 2008). 
Focusing on Media, the complex nature of online identity, as the understanding of participants in a more granular way was crucial for social machine observation and design was studied. ${ }^{47}$ They studied the personas that were portrayed by participants in a social machine that produced creative media content, and discovered that inconsistent or misleading representations of individuals do not necessarily undermine the system in which they were participating.

Because relationships exist at places of work, identity enactment is also prevalent. There was an attempt to expand on the knowledge of how follower identities were socially enacted. The research was empirically founded in the qualitative traditions by interviewing members of a highly specialized and diversified team at a Danish company, Novo Nordisk. The study showed how follower identity was placed amidst a multitude of identities, identity work and enactments that influenced how those individual understood 'who am I as a follower?'48

A study, too, explored "identity enactment" within the context of a job training program that pushed its adult students to adopt certain work-related identities. Drawing on analyses of long-term participant observations, longitudinal interviews, and written artifacts, their study revealed the tensions, adjustments, and reorientations that occurred when adults' conceptions of their current and future identities collided with different, even disparate, models of the professional people they were asked to become. Also, job training was perceived as a prime context for identity construction and spoke to the complicated relationship of identity formation to skills development. ${ }^{49}$

All the studies above prove the usefulness of the identity theory in a study of any data: academic, workplace, media, nationality and ethnicity. Thus, the applicability of this theory in examining the kinds of identity that are enacted for the deceased in condolence messages is laudable. Also, these studies did not use the identity theory to examine messages of condolence, my motivation for the present study. On the other hand, studies have investigated condolence messages as well, which are presented in the next section below.

47. A. Guy and E. Klein, "Constructed identity and social machines: a case study in creative media production," in International World Wide Web Conference Companion (Seoul, Korea, 2014).

48. A. Rasmussen, Fellowship as an identity enactment (Copenhagen: Copenhagen Business School, 2012).

49. Hull and Zacher, 2007. 


\section{Studies on Condolences}

This section reviews studies on condolence messages. A number of studies have investigated condolence messages as a speech act, in many directions. Examples are presented below:

First, embracing a cross-cultural approach, there was a comparison of the expression of condolences between Americans and Japanese participants. Discourse Completion Task (DCT) was used to elicit data and her participants were asked to "express" themselves during a condolence in two given situations. ${ }^{50}$ The data were analyzed according to semantic formulas. The analysis confirmed five patterns, which included: 1 . Acknowledgement of the death with interjections like "oh" or "oh my God"; 2. Expression of sympathy like "I'm so sorry"; 3. Offer of assistance like "is there anything I can do?"; 4. Future-oriented remarks which took the form of words of encouragement or practical advice, like "try not to get depressed", and 5. Expression of concern which relates to showing care for the well-being of the speaker and/or their family and includes questions such as, "How are you doing?". Adopting the same cross-cultural approach, another study investigated the condolences responses in English and Persian. ${ }^{51}$ The study found that Persian responses were more celestial and collectivist in nature while English condolence responses were more terrestrial and individualistic. Again, there was an exploration of the giving of condolences across English and Persian via short messages ${ }^{52}$. About 60 short messages were gathered. The analysis of the data indicated that there was a difference in the way people gave their condolences and it was argued that Persian messages were more direct and short, and signs of religious culture were found in them. However, the English messages were mostly indirect, sympathetic, and apologetic. Furthermore, though crosscultural, a study focused on novices' way of expressing condolences by exploring the speech act of giving condolences by EFL learners in Iran. ${ }^{53}$ The study employed DCT as tasks, where 10 male and 35 female Iranians were recruited. The study revealed that some learners performed the speech act of condolence like their English counterparts, while some of these learners performed this speech act like they do in Persian.

In a slightly different direction, another study investigated the patterns in condolences, by examining how cultural norms and values imparted condolences

50. Elwood, 2004.

51. P. Reza and M. Mostafa, "Investigating condolences responses in English and Persian," International Journal of Research Studies in Language Learning 2, no. 1 (2012): 39-47.

52. Behnama, Hamed, and Asli, "An investigation of giving condolences in English and Persian via short messages," Social and Behavioral Sciences no. 70 (2013): 1679-1685.

53. L. Samavarchi and H. Allami, "Giving condolences by Persian EFL learners: a contrastive socio-pragmatic study," International Journal of English Linguistics 2, no. 2 (2012): 71-78. 
in the Iraqi community. ${ }^{54}$ It was revealed in the study that there were five most common and basic patterns of responses and five minor categories: Acknowledgement of death, Expressions of sympathy, Offer of assistance, Futureoriented remarks, Expressions of concern, Sharing similar experience, Making statements of not knowing, Making statements of lacking words, Expressing surprise, and Making related questions and comments.

There was a further exploration of the condolence messages in a monocultural setting. ${ }^{55}$ What was done, here, differently from the previous studies was that there was the introduction of the variables gender, age and social distance in the study. DCT tasks were used to extract data from 40 male and 40 female Iranian students. Their study revealed eight categories, of which examples were Direct condolence and Apologies. Also, they found that the condolence strategies used by Iranians were influenced by their religion. Following the same mono-cultural style, the strategies Iranian native speakers of Farsi used when responding to an obituary note was investigated ${ }^{56}$. Data were collected and analyzed from the condolence notes on a deceased contemporary Iranian actor in 2008. Two hundred comments were analyzed to examine the strategies used in expressing condolences. The findings showed that these native speakers expressed condolences differently.

Using a different set of condolences, there was an examination of the speech act of condolences in Jordanian Arabic that were conveyed via a social network site, i.e. Facebook. The data focused on the condolences made in response to an obituary status update on a deceased contemporary Jordanian actor in 2011. Based on 678 posted comments, the researcher was able to identify seven major strategies in the commentary, which included: praying for God's mercy and forgiveness for the deceased, reciting Quranic verses, enumerating the virtues of the deceased, expressing shock and grief, offering condolences, realizing death is a natural part of life; and using proverbs and sayings. The results revealed that the strategies were attributed to the respondents' religious orientation (i.e. Islam). Moreover, the findings also indicated that the majority of condolences in Jordanian comments were affiliated to faith and religious beliefs.

Like the study on strategies and gender, a further study explored the condolence strategies used by Arab native speakers (L1) towards a Hebrew (L2) native speaker in Hebrew (L2). ${ }^{57}$ The participants in that study were 85 Arab lecturers who responded to a college condolence announcement by e-mail which was addressed to a Hebrew native-speaker colleague who lost his daughter.

54. Yahya, 2010.

55. Lotfollahi and Rasekh, 2011.

56. M. Farnia, "'May God forgive His sins': Iranian strategies in response to an obituary note," Komunikacija i kultura Online: Godina II, Broj 2 (2013): 315- 323.

57. T. M. Murad, "'May Allah not let you experience another sorrow": condolence strategies used by lecturers who are native speakers of Arabic L1 toward their colleague who is native speaker of Hebrew in Hebrew L2," Theory and Practice in Language Studies 3, no. 1 (2013): 17-22. 
Frequencies and percentages were considered. A finding of the study was that the main condolence strategy used by the respondents was 'religion expressions'. Other strategies such as acknowledgement of death, expression of sympathy, offer of assistance, future-oriented remarks, expression of concern, appreciation of the dead, direct condolence and others were less frequently used. The findings also showed that the females initiated more condolence utterances in the same response than males though the study revealed that gender did not play an important role in the frequencies of the condolence strategies.

Moreover, a study examined the move structure and the communicative function in messages of condolences posted in the portals of International Centre for Theoretical Physics (ICTP)..$^{5}$ Employing a non-cultural approach, they examined patterns in the condolences like earlier discussed studies in addition to the lexicogrammatical features which highlighted the social functions of condolence messages in the world, in general, since the letters of condolences used for this study were written by people all over the world. They found that out of the nine patterns that were used, six of the moves were obligatory and the rest were optional.

Besides, a study investigated the proper construction of condolence messages in mitigating misunderstandings and preventing good intentions from being misinterpreted, by examining how Malaysian SMS condolences were composed, i.e. what semantic functions they did fall under. ${ }^{59}$ Analyzing 36 authentic condolences written in English via SMS by local friends to a local Chinese female recipient, Malaysian SMS condolences were found to mainly consist of eight semantic functions. Those which expressed concerns via directives and wishful thinking were least preferred whilst those which eulogised the deceased and expressed uncertainty were most preferred.

Last, a work presented a sociolinguistic examination of different methods for expressing condolences. ${ }^{60}$ After a death in the family, she collected thirteen instances of condolences which she analyzed using the framework of Linguistic Politeness. She identified three strategies for expressing condolences that ranked from most independence-oriented to most solidarity-oriented: (1) acknowledgment of sympathy, (2) question of concern, and (3) inquiry for information. Also, she examined the risks and payoffs involved in the specific tactics classified under the three strategies, and the correlation between the choice of strategy and the relationship of the interlocutors.

It can be seen from the above studies that condolence messages have been extensively studied, with particular attention on the semantics, strategies, moves,

58. A. E. Kongo and K. W. Gyasi, "Expressing grief through messages of condolence: a genre analysis," African Journal of Applied Research 2, no. 2 (2015): 61-71.

59. C. H. Kuang, "Functions of Malaysian condolences written in text messages," Pertanika Journal of Social Science \& Humanities 23, no. 1 (2015): 1-19.

60. Williams, 2015. 
gender, and religion amid other various cultural contexts. However, the above numerous reviewed studies on condolence messages did not examine the construction of identities for the deceased in such messages. The study ${ }^{61}$ that used a similar data to the present study did not consider identity construction, but focused on the move structure and the communicative function in messages of condolences. Hence, the present study seeks to examine the kinds of identity enacted for the deceased in messages of condolences posted in the portal of ICTP, when one of its members passed away.

\section{Methods}

The present study employed a qualitative approach. A qualitative research is concerned about finding out how people make sense of their lives, experiences and the structures of the world. ${ }^{62}$ Qualitative research analysis embraces multiple methods and research practices for undertaking research of field or life situations that are reflective of everyday life groups, societies and organizations. ${ }^{63}$ The qualitative approach chosen in the present study is content analysis (specifically, textual analysis). Content analysis is a technique for examining information, or content, in written or symbolic material (e.g., pictures, movies, song lyrics, etc.), allowing the researcher to observe the content (i.e., messages, meanings, etc.) in a source of communication (i.e., a book, article, movie, etc.). ${ }^{64}$ Further, content analysis is nonreactive because the process of placing words, messages or symbols in a text to communicate to a reader or receiver occurs without influence from the researcher who analyses its content. ${ }^{65}$ From this perspective, this research aimed to describe the construction of identity for the deceased in condolence messages posted in the portals of International Centre for Theoretical Physics (ICTP), when one of its members, Professor Gallieno Denardo, passed away. ICTP is a wide world organization for Physicists. This research site was selected mainly because of the national variations of members. Therefore, the present study intends to examine the ways by which some particular groups of people use the language of condolence to enact identities for the deceased.

The total data obtained from the site were one hundred and five (105) messages of condolences of which some were written in Arabic, English, French

61. Kongo and Gyasi, 2015.

62. J. W. Cresswell, Research design: qualitative \& quantitative approaches (California: Sage, 1994).

63. K. Punch, Introduction to social research: Quantitative and qualitative approaches (London: Sage, 1998).

64. L. W. Neuman, Basics of social research: quantitative and qualitative approaches (Boston: Pearson Education, 2007).

65. Ibid. 
and German. Using purposive sampling technique, I sampled ninety-five (95) messages of condolences written in English, which was informed by my ability to read and comprehend the English language. Again, twenty out of the ninety-five (95) condolence messages were selected for this research. The reason for selecting the twenty messages of condolence was on the basis that only one message of condolence would be chosen from a country, and the messages of condolences written by a group of persons, and those without addresses were not chosen. Also, a cursory examination of the ninety-five messages revealed similar themes; thus, the limitation to twenty out of the ninety-five.

The data (messages of condolences) were read thoroughly and coded. The coded items were later grouped into different identity categories. To ensure reliability of the coded and grouped items, I asked three other colleagues who are well vexed in the area of identity studies to re-examine the data. Consequently, the inter-rater reliability between my three colleagues regarding the labelling of the identities was $80 \%$. Upon further discussions with my colleagues, we tried to resolve the differences and concluded that the inter-rater reliability was justifiable.

\section{Analysis and Discussion}

This section presents analysis and discussion of the data. The various identities that were enacted for the deceased will be discussed one after the other, and each of the identities will be illustrated with evidence from the data. The identities are discussed based on their frequency of occurrence in the data. In terms of the kinds of identity that are enacted for the deceased, the data revealed two broad identities for the deceased - Role identity and Social identity.

\section{Role Identity}

Role identity is enacted through the duties that are performed ${ }^{66}$. In the condolence messages, the deceased is projected as a father, friend, colleague, leader, achiever, and an academic. First, a summary of the role identity which is presented in frequencies and percentages is found in Table 1.

66. Turner, 1987. 
Table 1. Types of Role Identity

\begin{tabular}{|l|c|c|}
\hline Types & Frequency (N) & Percentage (\%) \\
\hline Friend & 25 & 25.8 \\
\hline Academic & 22 & 22.7 \\
Colleague & 19 & 19.6 \\
Father & 14 & 14.4 \\
Leader & 11 & 11.4 \\
Achiever & 6 & 6.2 \\
\hline Total & 97 & 100 \\
\hline
\end{tabular}

In Table 1, identity as a Friend was the highest, 25(25.8\%) with identity as Academic, 22 (22.7\%), and Colleague, 19(19.6\%), placing second and third respectively. The least was Achiever, with $6(6.2 \%)$. The highest use of identify as a Friend in the messages is suggestive of the kind of relationship that the deceased had with all he interacted with. Perhaps, as a man with many responsibilities, knowledge and exposure, he was expected to maintain very formal relationship with all his interactions; however, he developed a very good relationship with such individuals, earning him that identify as a Friend in the data. Again, the frequent use of identity as a Father in the data resonates the concept of "Salience" which is the different social structural positions held by an individual and the possible impact of each on the person's performance, ${ }^{67}$ and "Salience hierarchy" which addresses which identity a person will enact in a situation where more than one role may be appropriate. ${ }^{68}$ With relevant examples, all the role identities identified in the data are discussed below:

Identity as a Friend

First, for many of the well-wishers, the deceased was a friend. Some illustrations are found here:

Extract 1: I am depressed to hear that one of my best friends died suddenly.

Extract 2: I am deeply distressed about the news of the passing away of our good friend Gallieno.

Extract 3: Professor Denardo was a good friend of Ghana Atomic Energy Commission (GAEC). Professor Denardo was a friend of Jordan.

Extract 4: I was shocked and saddened to learn about the sudden demise of my dear friend Gallieno.... He was more than a friend.

From extracts 1-4, the deceased is projected as a friend. He is projected not as any mere friend but a "best friend", "good friend" and a "dear friend" in extracts

67. P. A. Thoits, "Identity structures and psychological well-being: gender and marital status comparisons," Social Psychology Quarterly 55 (1992): 236-56.

68. Stryker, 1968. 
1, 2 and 4 respectively. The adjective really indicates that the deceased was a very good friend indeed. The friendship was extended to individuals, agencies, and members of a community and even, nations. In the extracts above, "my dear Friend", "a good friend of Ghana Atomic Energy Commission (GAEC)", "our dear friend", and "a friend of Jordan", are evidence of his friendship towards these agencies, communities, and nations. The use of the singular first person pronoun, "my" is indicative that the deceased was a friend to an individual, on that personal level, which resonates the individualistic nature of offering condolences by English condolences as found in a study. ${ }^{69}$ Again, a friend of "Ghana Atomic Energy Commission (GAEC)" is suggestive that he was "nice" and "good" to that agency, possibly, in terms of the support offered to that agency - the visits and the share interest in ensuring that all was well with the agency as a good friend will do. The use of the third person plural possessive pronoun, "our" is also indicative that the late was a friend to many individuals within the larger circle of work, which was even extended to nations, "a friend of Jordan". The beneficiaries of this friendship enjoyed the relationship so much that it was revealing in the data that "he was more than a friend", as found in Extract 4. What exactly that meant, only the writers could explain, but it can be deduced that it was a very positive relationship. Again, the various references to him as "Professor Denardo" and "Gallieno" show that his friendship was extended to colleagues as well as subordinates, cutting across all levels in his life. With this identity, a certain level of positioning is observed here. Positioning is "an event of identification, in which a recognizable category of identity gets explicitly or implicitly applied to an individual in an event that takes place across seconds, minutes, or hours" ${ }^{70}$ The activities of the deceased made the writers described him as a friend.

\section{Identity as an Academic}

Besides, the deceased was projected as an academic in the messages of condolence. In academia, like a discourse community, it has its own common goals, mechanisms of intercommunication, information exchange and feedback, specific genres, specialized lexis and a threshold level of expertise. ${ }^{71}$ It is often expected that a member of a community will reflect the practices of such a community - titles, activities, associations etc., and these reflections of an academic were found in the condolences:

69. Reza and Mostafa, 2012.

70. S. Wortham, "From good student to outcast: the student emergence of a classroom identity," Ethos 32, no. 2 (2004): 166.

71. J. M. Swales, Genre analysis: English in academic writing and research settings (Cambridge: Cambridge University Press, 1990). 
Extract 5: ... untimely death of Prof. Gallieno Denardo

Extract 6: He has been discussing with me some issues like subjects to be included in the programme, selection of participant's demonstrations and laboratory work....

Extract 7: ... it is a great pity... to lose such an active and valuable eminent professor

Extract 8: He was a motivated promoter of science in the developing world, helping young people to build their careers, and more advanced researchers to connect and to work together.

The numerous references to the deceased as a "Professor" and "eminent professor" project him as an academician since such address terms, in the form of the titles, are used in the academic community to indicate the ranks or the level of scholarship in this field. The use of titles such as "Professor" before the name, which are pre-modifiers, are used to revere the deceased, ${ }^{72}$ confirming the findings of other studies ${ }^{73}$ that adjective (as an example of modifiers) was used to maintain a distant relationship with the reviewer. Again, in Extract 6 above, we get a glimpse of this academic identity in the structure "like subjects to be included in the programme" as well as the use of "a promotor of science" in Extract 8. These are all related to the discourse of academics.

This academic identity also foregrounds the professional identity of the deceased, as a scientist and physicist. Illustrations of this identity are given in the extracts below:

Extract 9: He was a great scientist and person.

Extract 10: He was an excellent and dedicated promoter of scientific cooperation.

Extract 11: We will remember him as an enthusiastic physicist.

In Extract 9, the deceased is presented as "a great Scientist" while Extract 11 projected him as an "enthusiastic physicist". It can be seen that the deceased was a well-established scientist and physicist; he is presented as a great person in that direction, and somebody who loved what he was doing, too, confirming the assertion that a teacher's professional identity is shaped, in part, from the appropriation of the gaze that the others return to that teacher. ${ }^{74}$ Thus, through the condolences, the professional identity of the deceased is brought to bear.

Identity as a Colleague

72. Kongo and Gyasi, 2015.

73. J. B. A. Afful and I. N. Mwinlaaru, "The construction of multiple identities in the acknowledgement section of a Masters dissertation," English for Specific Purposes World 30, no. 9 (2010): 1-26.

74. M. Solari and M. E. Ortega, “Teachers' professional identity construction: a sociocultural approach to its definition and research," Journal of Constructivist Psychology (2020): 1-31. 
Another identity that is constructed for the deceased in the data is colleague. The deceased is represented as a colleague by many of the sympathizers who offered their condolences:

Extract 12: We are still shocked by the news of Gallieno's death.

Extract 13: I was shocked and greatly saddened by the news that_Gallieno had died....

Extract 14: Please accept my personal and SIOF's deepest condolences for the sudden death of our colleague ... Gallieno Denardo.

Extract 15: I lost a most loyal and kind colleague at ICTP and its Scientific Community.

In extracts 12 and 13 above, the deceased is referred to by the first name, "Gallieno" but the full name, Gallieno Denardo, in Extract 14. The use of these address terms are indicative of a horizontal relationship between the deceased and the writers, revealing the social distance and the solidarity between the deceased and the writers of the condolences ${ }^{75}$. Again, in Extract 14 and 15, the deceased is specifically referred to as "a most loyal and kind colleague at ICTP and its Scientific Community". We also get some reference to him as "our colleague". In all these illustrations, the late is foreshadowed as a colleague. The act of recognition is at play here, which is any explicit or implicit action through which an individual seeks or receives recognition or by which an individual recognizes other people. ${ }^{76}$ Through the activities of the deceased, he was recognised as a colleague by the writers of the condolence, confirming the relational nature of identity. ${ }^{77}$

Identity as Father

Furthermore, the deceased is projected as a father in the data. Variously, the writers of these condolence messages refer to the deceased as a father. Examples from the data are provided below:

Extract 16: We really lost a great father.

Extract 17: I became very close with him through his fatherly care and counselling in order to see to it that initiated projects were well monitored and executed.

Extract 18: As a Senior Associate I hear the word orphaned in my mind...

75. Afful and Awoonor-Aziaku, "Naming in master's thesis acknowledgements within two Ghanaian university departments," Africology 10, no. 9 (2017): 252-273; Afful and Mwinlaaru, 2010.

76. C. Coll and L. Falsafi, "Learner identity. An educational and analytical tool," Revista de Educacion 353 (2010): 211-233.

77. Solari and Ortega, 2020. 
In Extract 16 above, the writer states that he has lost a great father. Perhaps, the deceased is not the biological father of the writer; however, due to the kind of relationship that he might have had with the deceased, the writer refers to the deceased as a father. Extract 17 gives evidence of the identity enacted for the deceased as a father, that is, "for his fatherly care and counselling in order to see to it that initiated projects are well monitored and executed". It can be deduced from the extract that the deceased had a caring attitude of a father by counselling the young "ones" because of his experience, monitoring and seeing to it that such projects were executed "well" just as a father will do at home, ensuring that the little ones do not go astray, which compares with the findings of a study that found that fathers who consider nurturing role highly central to their sense of self engaged in significantly more interactional responsibility behaviours with their younger ones. ${ }^{78}$ The roles that a person performs give him or her a certain identity. ${ }^{79}$ The deceased cannot be father to all these sympathizers, but through the duties that he discharged, he was seen as a father, which can be described as a metaphorical use of the word 'father' 80 , affirming the idea that, semantically, condolences have a social meaning which refers to the language use, and this is to establish social relations and roles. ${ }^{81}$

Identity as a Leader

Apart from the fatherly, friendship and colleague roles that the deceased performed, he, also, occupied leadership positions. He assumed many leadership roles, crediting to him the identity of a leader. The extracts below illuminate this identity:

Extract 19: He worked very hard for the development of Science in the developing countries in his position as head of the Office of External Activities.

Extract 20: I will remember him as great leader who endorsed the visions of Abdus Salam ICTP.

Extract 21: As the chair of the TSOSA Committee.... We cherish his duty visits to Ghana.

In Extract 19 above, the deceased was the head of the Office of External Activities. As the head, he occupied a position that placed him above others, and he saw to the smooth running of activities under his care, leading others to

78. R. T. Rane and B. Mcbride, "Identity theory as a guide to understanding fathers' involvement with their children," Journal of Family Issues 21, no. 3 (2000): 347-366.

79. Stets and Burke, 2000.

80. Bowdle and Gentner, "The career of metaphor," Psychological Review 112, no. 1 (2005): 193-216; C. A. Hamilton, "Mapping the mind and the body: on W. H. Auden's personifications," Style 36, no. 3 (2002): 408-427.

81. Mwihaki, 2004. 
achieve targets. Extract 20 categorically states that the deceased is remembered "as a great leader" and that he sanctioned the visions of Abdus Salam ICTP, simply because he had the power to do so because of the role that he played as a leader in that ICTP community. Another evidence of his leadership roles is that he occupied the chair of the TSOSA Committee as captured in Extract 21. All these roles ascribe to him the identity, a leader. This leadership identity has been made possible because of the evaluation of the writers which is evident in the condolences, a description captured in the assertion that leaders can be considered effective if other people evaluate them as an effective leader; that is, "perceived leader effectiveness". ${ }^{82}$ In other words, the deceased is treated with perceived leader effectiveness skills because of what the writers of the condolences have said about him; however, he can aptly be described as a leader with "in- role performance" 83 per his many engagement with the activities of the group.

Imbedded in the leadership role is a modelling role, encapsulating the idea that given multiple identities, there are relationships among the different identities which will be activated in a given situation. ${ }^{84}$ The deceased is projected as a master to be learnt from:

Extract 22: I think we lost him but we did not lose him as a model in life.

Extract 23: He mentored me to supervise effectively to achieve positive results in our endeavors.

Extract 24: My association with Prof. Denardo afterwards through his instrumentation in my formation period in scientific research work in Italy....

Extract 25: I have really lost him as a mentor.

Extract 26: His office was always full of young people scientists seeking advice which he readily gave.

In Extract 22, it is implied that there is a lost physically, but there is no loss materially, in the sense that the deceased is worthy of being a model, which, to the community members, is not a loss in anyway. Again, his leadership position allowed him to mentor many individuals; that is, he "mentored" (Extract 23) that individual to achieve positive results. Good advice plus firm supervision made those individuals saw him as a mentor. It is illuminating that the deceased is a mentor since he was instrumental in the formative period of these young ones (Extract 24). The formation period is critical as it determines what one becomes of in future, and strict mentoring is needed here- this the deceased gave to this

82. J. Prochazka, M. Vaculik, P. Smutny and S. Jezek, "Leader traits, transformational leadership and leader effectiveness: a mediation study from the Czech Republic," Journal of East European Management Studies 23, no. 3 (2018): 474-501.

83 Ibid.

84. Stets and Burke, 2000. 
young scientists (Extract 26), which enumerates the virtues of the deceased, a finding also of a study.

Identity as an Achiever

Lastly, in the data, the deceased is perceived as an achiever because achievers earn credits for their hard works. The deceased received awards, helped create successful scientific communities, and trained young ones. Evidence of these in the data are presented below:

Extract 27: It was an honor to present him with SPIE's Educator Award.

Extract 28: He helped to create the entire global community of talented physicists.

Extract 29: This is the great man who succeeded through the ICTP Office of External activities within the Affiliated Centers to train young scientists to obtain M.Phil and Ph.D. in Physics in Africa.

Extract 30: He salvaged brain drain on the continent and promoted brain gain in Trieste through ICTP visits of such scientists.

In Extract 27 above, the deceased received awards like SPIE's Educator Award. In addition, he trained young scientists to obtain M. Phil and Ph. D in Physics in Africa (Extract 29), and he helped stop brain drain but increase brain gain (Extract 30). These instances project the deceased as an achiever. This projection is in line with what is done in obituaries, where obituary notices served as a socially oriented practice for the expressions of positive feelings and compliments about the deceased. ${ }^{85}$ Again, this role can best be described as an act of recognition, which is "conditioned by the intricate interplay between the social context, the activity that people are involved in, and not the least, by the discursive and non-discursive actions through which the recognized person participates in the activity". ${ }^{86}$ In other words, it is not the intention of those who perform an action that defines it as an act of recognition; rather, it is the effect that this action has on the other person, depending on that person's interpretation of it, its meaning within the context where it takes place, and the impact that the significant other has on the recognized person, that emanates this act of recognition. ${ }^{87}$

This section has discussed the Role identity of the deceased in the data, where he is projected mainly as a friend, academic and colleague, alongside other

85. Farnia, 2013; R. Pishghadam and M. M. Morady, "Investigating condolence responses in English and Persian," International Journal of Research Studies in Language Learning (2012).

86. L. Falsafi, Learner identity: a sociocultural approach to how people recognize and construct themselves as learners (Universitat de Barcelona, 2010), 31.

87. Solari and Ortega, 2020. 
identities like father, leader and achiever. These different roles prove that, indeed, identity is dynamic and contextual, depending on the salience of the different classifications $^{88}$, and that different identities become active as the situation changes and relevant self-categorization stimuli change. ${ }^{89}$ Again, the different roles identified in the study prove the assertion that, clearly, language can systematically be varied to construct varying and different identities ${ }^{90}$, and that language can be considered as a site for the construction of selfidentification or group affiliation since language is a key element in identity formation and identity is a sense of self or proves a sense of belonging. ${ }^{91}$

\section{Social Identity}

This part of the analysis presents Social identity which considers how individuals define their own identities with regard to social groups and that such identifications work to protect and bolster self-identity. ${ }^{92}$ The analysis of the data revealed four main social identities enacted for the deceased: group membership, family, international figure and good personality. Table 2 below summarizes the distribution of these social identities:

Table 2. Types of Social Identity

\begin{tabular}{|l|c|c|}
\hline Types & Frequency (N) & Percentage (\%) \\
\hline International Figure & 27 & 42.9 \\
\hline Member of a Group & 15 & 23.8 \\
Member of a Family & 13 & 20.6 \\
Good Personality & 8 & 12.7 \\
\hline Total & 63 & 100 \\
\hline
\end{tabular}

According to Table 2, four Social identities, in varying proportions, were found in the data. Identity as an International Figure was highest, 27(42.9\%), followed by identity as a Member of a Group, 15(23.8\%). The least occurring social identity was Good Personality, (12.7\%). The frequent use of identity as an International Figure is not surprising as ICTP is an international group with membership from almost all over the world. Besides, the deceased seems to have interacted with members of the group from all over the world because of the various positions he occupied as revealed in the discussion under Role identity in the previous section of the analysis and discussion of this present study. These social identities alongside evidence from the data in support of these findings are discussed further.

88. Turner, 1987.

89. Stets and Burke, 2000, 231.

90. Afful and Mwinlaaru, 2010.

91. Nematzadeh and Narafshan, 2020.

92. Turner, 1987. 
Identity as an International Figure

First, despite all the many identities that has been enacted for the deceased so far, the writers of the condolence messages also created another identity for the deceased as an international figure. Evidences of this identity are offered below:

Extract 31: He was one of the outstanding international fellows and he had many friends all over the world.

Extract 32: I can confirm that mother Africa specifically and the developing World in general has lost an ICONE: EL PROFESSORI.

Extract 33: He supported our initiative for collaboration in the Balkans and Southeast Europe very strongly.

Extract 31 above demonstrates that the deceased was an outstanding international fellow, and he had many contacts with many people all over the world. In Extract 32 above, he is seen as having relations with Africa and the developing world. He also had dealings with the Balkans and Southeast Europe (Extract 33). Apart from the places that have been named in the condolence messages, the addresses of the writers of these condolences confirm that the deceased was an international figure to have received tribute from all these individuals across the globe:

Extract 34: Miltcho Dnailov, Laser Laboratory, Italy.

Extract 35: Goren Djordjevic, Faculy of Science, Serbia.

Extract 36: Mohamed Ewis, Director of HEQAA, Faculty of Sciences, Egypt.

Extract 37: Amy K. Flatten, The American Physical Society, USA.

Extract 38: J. O. Adeniyi, Physics Department, Nigeria.

Extract 39: Francis K. Allotey, Society of African Physicists \& Mathematicians, Ghana.

The underlined names of places in the extracts (34-39) above designate the various dwellings from where individuals sent their condolences. These many places underscore the fact that the deceased had connections, in one way or the other, directly or indirectly, with all the writers of these condolences, bringing forth his identity as an international figure. Here, too, we see evidence of depersonalized identity based on group membership which is imbued with positive aspects..$^{93}$ In other words, the deceased has been defined through the group.

Identity as a Member of a Group

Second, the true identity of the deceased as an academic, the joy with which he discharged his duties in addition to the desire to remain loyal to the

93. Turner, Hogg, Oakes, Reicher, and Wetherell, 1987. 
community in which he found himself, made him joined other professional associations, earning him the identity of a member of a group. This is an example of social identity, where individuals define their own identities with regard to the social groups ${ }^{94}$ Examples of this identity as a member of a group in the data are as follows:

Extract 40: I wish to extend my deepest sympathy to all ICTP, all national scientists, researchers, academicians, and all the International Scientific Community.

Extract 41: He was a member of the first SESAME Training Committee.

Extract 42: He participated in many activities run by ICTP together with UNESCO $\underline{\mathrm{SC}}$.

The extension of sympathy to these various groups is an indication that these groups have been bereaved, in that, the loss of that member has left distress in their hearts; hence, the writer of the condolence (Extract 40) sympathizes with "ICTP, all national scientists, researchers, academicians, and all the international Scientific community", indicating that the deceased had associations with them. Extract 41 openly mentions that the deceased was a member of the first SESAME Training Committee. In other words, he was a member of that Training committee that was formed by SESAME. In addition, he participated in many activities ran by ICTP together with UNESCO SC. An individual cannot participate "in many of the activities" (Extract 42) of a group if he or she is not a member of that group - a projection of that identity as a member of a group. Thus, the deceased is viewed as a person who acted in the context of social structure that names one another and themselves in the sense of recognizing one another as occupants of positions. This naming invokes expectations with regard to each other's and one's own behaviors. ${ }^{95}$

\section{Identity as a Member of a Family}

Another group identity of the deceased is family. The data set is indicative that the deceased had immediate family, but he belonged to the extended family unit too:

Extract 43: On behalf of EBASI and myself, we extend our deeply felt condolences to the family of Professor Gallieno Denardo.

Extract 44: Please convey my condolences to the bereaved family and his wife.

Extract 45: Sincere condolences to Gallieno's family.

Extract 46: Please convey our deepest sympathy to his family.

94. Tajfel, 1978.

95. McCall and Simmons, 1978; Stryker, 1980. 
In extracts 43-46 above, the writers of the condolences express their sympathy towards the family of Professor Gallieno Denardo, which are conveyed to both the immediate family member, "his wife" (Extract 44), and the extended family, "Gallieno's family"(Extract 45). The sympathizers express these condolences to the family because every individual is born into a family; accordingly, though group members, friends and colleagues may be affected by the death of the professor, it is the family that will carry the weight most for the deceased was a husband and might be a brother or an uncle to some individuals as well. His death will automatically cause pain to these family members; consequently, the need to console these family members. This identity as a member of family also appeals to the inherently dialogic nature of the process ${ }^{96}$ in that our senses of ourselves are fashioned in relation to the identities of others. ${ }^{97}$ Thus, the deceased gets an identity as a member of family because of the family he belonged to.

\section{Identity as a Man with Good Personality}

Finally, the deceased is presented as a man with good personality. This identity is the sum total of who the deceased actually was. Many noun phrases and descriptive adjectives have been used in the data to denote the good personality of the deceased. Examples are given below:

Extract 47: Professor Denardo will be remembered among us as a man of wisdom, courage and help.

Extract 48: He was a very kind person and he supported our initiative for collaboration in the Balkans and Southeast Europe very strongly.

Extract 49: He had time for everybody.

Extract 50: He as tough and tender with his actions and committed to duties.

Extract 51: He was selfless, devoted, honest and pragmatic.

Extract 52: ... he was a human being with a big heart- which never failed when it comes to sharing it with others.

Many good qualities have been attributed to the deceased, projecting him as a very good person. He is severally designated as "a man of wisdom, courage and help" , "enthusiastic and skillful support", "selfless, devoted, honest and pragmatic", "tough and tender with his actions and committed to duties" and "human being with a big heart", just to select a few of the instances. The use of these linguistics elements like nouns, adjective and verbs variously project the deceased as a man with good personality. In acknowledging memories of the deceased, the sympathizers recall or enumerate the virtues or some distinctive, well-mannered attitudes of the deceased. ${ }^{98}$ It is not surprising to have the

96. Bakhtin, 1981.

97. Hull and Zacher, 2007.

98. Kongo and Gyasi, 2015. 
deceased projected like this in the sense that, usually, in some societies like Ghana, the dead are to be held in high esteem because it is believed that they can bring blessings or curses, a belief probably shared in many cultures over the world, considering the fact that these condolences were sent from across the globe and that in each of the condolence messages, the deceased is projected as somebody who possessed good attributes. When personality characteristic is considered in some culture to be a desirable leadership characteristic, then its influence on the leader's acceptance and leadership effectiveness would be stronger. ${ }^{99}$

In sum, this section has considered the various roles that have been enacted for the deceased in the messages of condolence, both role identity and social identity. Here, the deceased can be described as having polyphonic identity, a finding similar to a study that investigated identity of teachers and found that teacher identity is polyphonic, as it is inhabited by multiple voices with different origins and levels of generality. ${ }^{100}$ With Role identity, the deceased was projected mainly as a friend, academic and colleague. There were also mentions of his identity as father, leader and achiever. Membership in a group and family as well as an international figure and good personality were his social identities which were acknowledged in the messages of condolence. Thus, we see evidence that being and doing are both central features of one's identity ${ }^{101}$, in that, in expressing condolences, there is both being and doing; that is, what the deceased was (being) and what he did (doing), which were clearly expressed in the data analyzed.

\section{Conclusion and Implications}

The study investigated the kinds of identity that are enacted for the deceased in messages of condolences. Adopting a textual analysis of the qualitative approach, the study analyzed twenty condolence messages purposely sampled from condolence messages posted in the portals of International Centre for Theoretical Physics (ICTP), when one of its members passed away. The analysis of the data revealed two main identity types for the deceased: Role identity and Social Identity. The major Role identity enacted for the deceased, metaphorically, was Father, and the least role was Achiever. Second, identity as an International Figure was dominant in the Social roles, but Good Personality was used less frequently. The different identities such as father and mentor enacted in the

99. Prochazka et al., 2018.

100. M. Prados, M. Cubero, A. Santamaria and S. Arias, "The teaching self in the university: self-positions and voices in the narrative identity/ies construction of university teachers," Infancia y Aprendizaje 36, no. 3 (2013): 309-321.

101. Stets and Burke, 2000. 
present study were derived from the different roles that the deceased played when alive, and his association with others created those numerals identities for him. It must be noted that identities do not spring out just out of the bloom, but through the different roles that individuals play in their everyday life situations, including our associations with other people, in particular, and different groups, in general. Thus, there is the need for responsibilities to be discharged well, for through these, we create our own identities. Truly, the levels of identity are dynamic and contextual, depending upon the salience of the different classifications. ${ }^{102}$ Different identities become active as the situation changes and relevant self-categorization stimuli change. ${ }^{103}$

The study has implications for contributing to scholarship and theory. First, the study has contributed to the growing literature on condolence messages. Condolences have extensively been studied with attention on semantics, strategies, moves, gender, religion, and amid other various cultural contexts. The present study which examined the kinds of identity enacted for the deceased in messages of condolences posted in the portal of ICTP, when one of its members passed away, has added to these studies on condolence messages by revealing that the deceased was, variously, projected as a father, mentor, leader and many more, with the dominant ones father. Thus, the present study help establish that condolence messages do not only reveal their inherent strategies and patterns, values and cultures from both mono and cross cultural perspectives, but that condolence messages are good grounds for enacting identities, projecting the different social roles which individuals can play in different contexts. Second, theoretically, the present study adds to the usefulness of the Social Identity Theory (SIT) that underpins the present study - that individuals define their own identities with regard to social groups and that such identifications work to protect and bolster self-identity. Several studies have employed SIT and have successfully managed, analysed and interpreted their data in many genres like academics, media, work place, nationality, and ethnicity. These studies have proven the usefulness of the identity theory in a study of any data, whether academic, at the workplace, media or in determining how national and ethnic identities are constructed. The adoption of this theory in the present study adds to the usefulness of the theory in interpreting findings and highlighting the various identities enacted for the deceased in condolence messages.

It is recommended that further studies investigate identity construction of national figures such as late presidents to ascertain the different identities enacted for such deceases in the messages of condolence. Also, cross-cultural studies could also examine identity construction in messages of condolence in Ghana and with other cultures to ascertain whether the patterns and expressions used in these kinds of situations may vary in different contexts and different cultures.

102. Turner, 1987.

103. Stets and Burke, 2000, 231. 


\section{Bibliography}

Aapengnuo, C. M. Threat narratives, Group identity and violence: a study of the Dagomba, Nanumba and Konkomba of Northern Ghana. Unpublished MPhil Thesis. George Mason University, 2008.

Afful, J. B. A. and L. Awoonor-Aziaku. "Naming in master's thesis acknowledgements within two Ghanaian university departments." Africology 10, no. 9 (2017): 252-273.

Afful, J. B. A. and I. N. Mwinlaaru. "The construction of multiple identities in the acknowledgement section of a Masters dissertation." English for Specific Purposes World 30, no. 9 (2010): 1-26.

Austin, J. L. How to do things with words. Cambridge: Harvard University Press, 1962.

Bailey, B. "The language of multiple identities among Dominican Americans." Journal of Linguistic Anthropology 10, no. 2 (2001): 190-223.

Bakhtin, M. M. "Discourse in the novel." Translated by C. Emerson and M. Holquist. In The Dialogic Imagination, edited by M. Holquist. Austin: University of Texas Press, 1981, 259-422.

Behnama, B., L. A. Hamedb and F. G. Aslic. "An investigation of giving condolences in English and Persian via short messages." Social and Behavioral Sciences no. 70 (2013): 1679-1685.

Bentley, S. V., K. Peters, S. A. Haslam and K. H. Greenaway. "Construction at work: multiple identities scaffold professional identity development in academia." Frontiers in Psychology 10, no. 628 (2019): 1-13.

Bowdle, B. F. and D. Gentner. "The career of metaphor." Psychological Review 112, no. 1 (2005): 193-216.

Clark, R. E. and E. E. LaBeff. "Death telling: managing the delivery of bad news." Journal of Health and Social Behavior 23, no. 4 (1982): 366-380.

Coll, C. and L. Falsafi. "Learner identity. An educational and analytical tool." Revista de Educacion 353 (2010): 211-233.

Creswell, J. W. Research design: qualitative \& quantitative approaches. California: Sage, 1994.

Dutton, J. E., L. M. Roberts and J. Bednar. "Pathways for positive identity construction at work: four types of positive identity and the building of social resources." Academy of Management Review 35, no. 2 (2010): 265-293.

Ellemers, N., S. Pagliaro and M. Barret. "Morality and behavioural regulation in groups: a social identity approach." European Review of Social Psychology 24, no. 1 (2013): 160193.

Elwood, K. "'I'm so sorry': a cross-cultural analysis of expressions of condolence." The Cultural Review, Waseda Commerical Studies Association, (Bulletin of Universities and Institutes) 24 (2004): 101-126.

Falsafi, L. Learner identity: a sociocultural approach to how people recognize and construct themselves as learners. Unpublished PhD Thesis. Universitat de Barcelona, 2010.

Farnia, M. "'May God forgive His sins': Iranian strategies in response to an obituary note." Komunikacija i kultura Online: Godina II, Broj 2 (2013): 315- 323.

Gao, J. Exploring the identity negotiation of east Asian graduate teaching assistants: case study of academic identity, social identity and teacher identity. Unpublished $\mathrm{PhD}$ dissertation. University of Kansas, 2019.

Gecas, V. “The self-concept.” Annual Review of Sociology 8 (1982): 1-33. 
Gergen, K. J. The saturated self: dilemmas of identity in contemporary life. New York: Basic Books, 1991.

Gholaminejad. R. "Identity construction and reversal conceptual transfer among Iranian EFL learners." HOW 24, no. 2 (2017): 1-15.

Guihang, G. and Z. Miao. "Identity construction of Chinese business English teachers from the perspective of ESP theory". International Education Studies 12, no. 7(2019): 20-27.

Guy, A. and E. Klein. "Constructed identity and social machines: a case study in creative media production." In International World Wide Web Conference Companion. Seoul, Korea, 2014.

Gyasi, K. W., A. E. Kongo, B. K. Agbenyo, W. Y. Lumor, P. Aopare and C. Koufie. "Identity and non-verbal communication: the case of UCC students on Master of Arts teaching communicative skills programme." African Journal of Applied Research (AJAR) 2, no. 2 (2015): 51-60.

Habermas, J. Theorie des Kommunikativen Hande Ins, Band I. Handlungs rationalita mtund gesell schatfliche Rationalisierang (Theory of communicative action, volume 1: Actions rationality and societal rationalization). Frankfurt am Main, Germany: Suhrkamp Verlag SchutzA, 1981.

Hamilton, C. A. "Mapping the mind and the body: on W. H. Auden's personifications." Style 36, no. 3 (2002): 408-427.

Hull, G. A. and J. Zacher. "Enacting Identities: an ethnography of a job training program." Identity 7, no. 1 (2007): 71-102.

Hülsse, R. "The discursive construction of identity and difference: Turkey as Europe's other?"Discussion paper presented at the ECPR Joint Sessions of Workshops (Workshop: The Political Uses of Narrative). Mannheim, 1999, 26-31.

Ibarra, H. "Provisional selves: experimenting with image and identity in professional adaptation." Administrative Science Quarterly 44, no. 4 (1999): 764-791.

Kongo, A. E. and K. W. Gyasi. "Expressing grief through messages of condolence: a genre analysis." African Journal of Applied Research 2, no. 2 (2015): 61-71.

Kuang, C. H. "Functions of Malaysian condolences written in text messages." Pertanika Journal of Social Science \& Humanities 23, no. 1 (2015): 1-19.

Lima, R. S., M. A. I. Silva, L. S. Andrade, F. S. N. Góes, M. A. Mello and M. F. C. Gonçalves. "Construction of professional identity in nursing students: qualitative research from the historical-cultural perspective." Revista Latino-Americana de Enfermagem 28, no. 3284 (2020).

Lotfollah, B. and A. Eslami-Rasekh. "Speech act of condolence in Persian and English." Studies in Literature and Language 3 no. 3 (2011): 139-145.

Mahendra, A. W. "Constructing identity: experiences of Indonesian ESP teachers in a language institute." English Language Teaching Educational Journal 3, no. 3 (2020): 229-240.

McCall, G. J., and J. L. Simmons. Identities and interactions: an examination of human associations in everyday life. New York: Free Press, 1978.

Mingfang, Z. and W. Qi. "Empirical research on relationship between college students' social identity and online learning performance: a case study of Guangdong Province." Higher Education Studies 8, no. 2 (2018): 97-106.

Moreno, L., A. Arriba and A. Serrano. "Multiple identities in decentralized Spain: the case of Catalonia." Regional \& Federal Studies 8, no. 3 (1998): 65-88. 
Murad, T. M. "'May Allah not let you experience another sorrow": condolence strategies used by lecturers who are native speakers of Arabic L1 toward their colleague who is native speaker of Hebrew in Hebrew L2." Theory and Practice in Language Studies 3, no. 1 (2013): 17-22.

Mwihaki, A. "Meaning as use: a functional view of semantics and pragmatics." Swahili Forum 11 (2004): 127-139.

Nematzadeh, A. and M. H. Narafshan. "Construction and re-construction of identities: a study of learners' personal and L2 identity." Cogent Psychology 7(2020): 1-19.

Neuman, L. W. Basics of social research: Quantitative and qualitative approaches. $2^{\text {nd }}$ Edition. Boston: Pearson Education, 2007.

Olshtain, E. and A. Cohen. "Apology: a speech act set." In Sociolinguistics and Language Acquisition, edited by N. Wolfson and E. Judd Rowley. MA: Newbury House. 1983, 18-35.

Pishghadam, R. and M. M. Morady. "Investigating condolence responses in English and Persian." International Journal of Research Studies in Language Learning (2012).

Prados, M., M. Cubero, A. Santamaria and S. Arias. "The teaching self in the university: self-positions and voices in the narrative identity/ies construction of university teachers." Infancia y Aprendizaje 36, no. 3 (2013): 309-321.

Pratt, M. G. "The good, the bad, and the ambivalent: managing identification among Amway distributors." Administrative Science Quarterly 45, no. 3 (2000): 456-493.

Pratt, M. G., K. W. Rockmann and J. B. Kaufmann. "Constructing professional identity: the role of work and identity learning cycles in the customization of identity among medical residents." Academy of Management Journal 49, no. 2 (2006): 235-262.

Prochazka, J., M. Vaculik, P. Smutny and S. Jezek. "Leader traits, transformational leadership and leader effectiveness: a mediation study from the Czech Republic." Journal of East European Management Studies 23, no. 3 (2018): 474-501.

Punch, K. Introduction to social research: quantitative and qualitative approaches. London: Sage, 1998.

Rane, R. T. and B. McBride. "Identity theory as a guide to understanding fathers' involvement with their children." Journal of Family Issues 21, no. 3 (2000): 347-366.

Rasmussen, A. Fellowship as an identity enactment. Unpublished MPhil Dissertation. Copenhagen: Copenhagen Business School, 2012.

Reza, P. and Mostafa, M. "Investigating condolences responses in English and Persian". International Journal of Research Studies in Language Learning 2, no.1 (2012): 39-47.

Rydell, R. J., A. R. McConnell and S. L. Beilock. "Multiple social identities and stereotype threat: imbalance, accessibility, and working memory." Journal of Personality and Social Psychology 96, no. 5 (2009): 949-966.

Salinas, D. and M. Ayala. "EFL student-teachers' identity construction: a case study in Chile". HOW 25, no. 1 (2018): 33-49.

Samavarchi, L. and H. Allami. "Giving condolences by Persian EFL learners: a contrastive sociopragmatic study." International Journal of English Linguistics 2, no. 2 (2012): 71-78.

Searle, J. R. Speech acts: an essay in the philosophy of language. Cambridge: Cambridge University Press, 1969.

Searle, J. R. “A classification of illocutionary acts.” Language in Society 5, no. 1(1976): 1-23.

Searle, J. R. Expression and meaning. Cambridge: Cambridge University Press, 1979.

Settles, I. H. "When multiple identities interfere: the role of identity centrality." Personality and Social Psychology Bulletin 30, no. 4 (2004): 487-500. 
Solari, M. and M. E. Ortega. “Teachers' professional identity construction: a socio- cultural approach to its definition and research." Journal of Constructivist Psychology (2020): 131.

Stets, J. E. and P. J. Burke. "Identity theory and social identity theory." Social Psychology Quarterly 63, no. 3 (2000): 224-237.

Stryker, S. "Identity salience and role performance." Journal of Marriage and the Family 4 (1968): 558-564.

Stryker S. Symbolic interactionism: a social structural version. Menlo Park: Benjamins, 1980.

Swales, J. M. Genre Analysis: English in academic writing and research settings. Cambridge: Cambridge University Press, 1990.

Tajfel, H. "Social categorization, social identity, and social comparison": In Differentiation between Social Groups: Studies in the Social Psychology of Intergroup Relations, edited by H. Tajfel. London: Academic Press, 1978, 61-76.

Tajfel, H. and J. C. "Turner. The social identity theory of intergroup behavior." In Psychology of Intergroup Relations, edited by S. Worchel and W. G. Austin. Chicago, IL: Nelson-Hall, 1987, 7-24.

Thoits, P. A. "Identity structures and psychological well-being: gender and marital status comparisons." Social Psychology Quarterly 55 (1992): 236-256.

Turner, R. H. "Social categorization and the self -concept: a social cognitive theory of group behavior." In Advances in Group Processes: Theory and Research, EDITED BY E. J. Lawlery. Greenwich, CT: JA, 1985, 77-122.

Turner, R. H. "The role and the person." American Journal of Sociology 84 (1987): 1-23.

Turner, J. C., M. Hogg, P. Oakes, S. Reicher and M. Wetherell. Rediscovering the social group: a self-categorization theory. Oxford: Blackwell, 1987.

Wortham, S. "From good student to outcast: the student emergence of a classroom identity." Ethos 32, no. 2 (2004): 164-187.

Williams, T. R. "Linguistic politeness in expressing condolences: a case study." Social Science \& Humanities 23, no. 1 (2015): 1-19.

Yahya, E. M. "A study of condolences in Iraqi Arabic with reference to English." Adab AlRafidayn 57 (2010): 47-70.

Yule, G. Pragmatics. Oxford: Oxford University Press, 1996. 